\title{
Desenvolvimento humano e segurança alimentar e nutricional: uma análise das políticas públicas para a agricultura familiar no estado de São Paulo, Brasil
}

\author{
Human development and food and nutrition security: an analysis of \\ public policies for family farming in the state of São Paulo, Brazil
}

\author{
Desarrollo humano y seguridad alimentaria y nutricional: un \\ análisis de las políticas públicas para la agricultura familiar en el \\ estado de São Paulo, Brasil
}

\author{
Jonatan Alexandre de Oliveira \\ jonatan.oliveira@unesp.br \\ Doutor em Geografia - Universidade Estadual Paulista - \\ Bolsista de Desenvolvimento Tecnológico Industrial do CNPq - Nível A \\ https://orcid.org/o000-0002-2326-5912 \\ Fábio Donato de Almeida Tardim \\ fabiodonatoat@gmail.com \\ Mestre em em Desenvolvimento e Cooperação Internacional - Universidade de Lisboa
}

\section{Resumo}

Empregando a 'abordagem de capacidades', em um primeiro momento, o presente trabalho busca esclarecer o vínculo conceitual entre o desenvolvimento e a garantia da Segurança Alimentar e Nutricional (SAN) demonstrando que a realização desse direito implica na obtenção de um estado de bem-estar nutricional, que permite ao titular usufruir de outros direitos plenamente, como o direito à educação, à saúde, à participação, entre outros. A segunda parte ocupa-se em apresentar o processo de conformação do espaço agrário brasileiro, com o intuito de fomentar a discussão sobre os ciclos que culminaram na reorientação do desenvolvimento rural brasileiro para a agricultura e para a ação estatal, articulando políticas sociais e de fomento a este segmento de combate à pobreza e geração de renda a partir da garantia da SAN. Buscou-se, então, analisar políticas públicas voltadas à agricultura familiar, nomeadamente o Programa de Aquisição de Alimentos da Agricultura Familiar (PAA), o Programa Nacional de Fortalecimento da Agricultura Familiar (PRONAF) e o Programa Nacional de Alimentação Escolar (PNAE). Observou-se que as políticas públicas analisadas apresentam comportamentos variados em relação às Regiões Administrativas (RA) do estado de São Paulo, reagindo à desigualdade dos índices de desenvolvimento socioeconômicos em conjunto com suas realidades agrárias. A
\end{abstract}

partir de suas delimitações e propósitos e atuando de maneira complementar, constatou-se que a estratégia nacional de combate à pobreza baseada no estabelecimento de circuitos curtos de produção, comercialização e consumo que, por sua vez, contribui para a consolidação de sistemas alimentares locais e para a garantia da SAN nas áreas mais socialmente vulneráveis.

Palavras-Chave: Políticas Públicas, Segurança Alimentar e Nutricional, Agricultura Familiar, Desenvolvimento Humano, Redução da Pobreza.

\begin{abstract}
By employing the 'capabilities approach', at first, the present work seeks to clarify the conceptual link between the development and the guarantee of Food and Nutrition Security (FNS) demonstrating that the realization of this right implies the attainment of a state of nutritional wellbeing, which allows the holder to enjoy other rights fully, such as the right to education, health, participation, among others. The second part deals with presenting the process of shaping the Brazilian agrarian space in order to foster discussion about the processes that culminated in the reorientation of Brazilian rural development towards agriculture and state action, articulating social policies and
\end{abstract}


promoting this segment with the purpose of fighting poverty and generating income from the FNS guarantee. We then sought to analyze public policies aimed at family farming, namely the Family Farming Food Acquisition Program (PAA), the National Family Farming Strengthening Program (PRONAF) and the National School Feeding Program (PNAE). It was observed that the analyzed public policies present varied behaviors in relation to the Administrative Regions of the state of São Paulo, reacting to the inequality of the socioeconomic development indices together with their agrarian realities. From its delimitations and purposes and acting in a complementary manner, it was stated a national strategy to fight poverty based on the establishment of short circuits of production, marketing and consumption that, in turn, contributes to the consolidation of local food systems and to FNS' guarantee in the most socially vulnerable areas.

Keywords: Public Policies, Food and Nutritional Security, Family Farming, Human Development, Poverty Reduction.

\section{Resumen}

Empleando el 'enfoque de capacidades', en un primer momento, este trabajo busca esclarecer el vínculo conceptual entre el desarrollo y garantía de la Seguridad Alimentaria y Nutricional (SAN), demostrando que la realización de este derecho implica el logro de un estado de bienestar. lo que permite al titular gozar plenamente de otros derechos, como el derecho a la educación, la salud, la participación, entre otros. La segunda parte se ocupa de presentar el proceso de conformación del espacio agrario brasileño, con el objetivo de promover la discusión sobre los ciclos que culminaron en la reorientación del desarrollo rural brasileño hacia la agricultura y la acción estatal, articulando políticas sociales y de desarrollo a este segmento. de combatir la pobreza y generar ingresos con la garantía SAN. A continuación, se intentó analizar las políticas públicas orientadas a la agricultura familiar, a saber, el Programa de Adquisición de Alimentos de la Agricultura Familiar (PAA), el Programa Nacional de Fortalecimiento de la Agricultura Familiar (PRONAF) y el Programa Nacional de Alimentación Escolar (PNAE). Se observó que las políticas públicas analizadas presentan comportamientos diferenciados en relación a las Regiones Administrativas
(AR) del estado de São Paulo, reaccionando a la desigualdad de los índices de desarrollo socioeconómico junto con sus realidades agrarias. Con base en sus límites y propósitos y actuando de manera complementaria, se encontró que la estrategia nacional de combate a la pobreza se basa en el establecimiento de circuitos cortos de producción, comercialización y consumo, lo que a su vez contribuye a la consolidación de los sistemas alimentarios locales. y garantizar SAN en las zonas más vulnerables socialmente.

Palabras clave: Políticas Públicas, Seguridad Alimentaria y Nutricional, Agricultura Familiar, Desarrollo Humano, Reducción de la Pobreza. 


\section{Introdução}

Uma das mais inerentes condições humanas, e sobre a qual este trabalho se desenvolve em torno, a fome costuma tornar-se objeto de acrescentado interesse nos momentos mais dramáticos vividos no seio das sociedades. Segundo o mais recente relatório de amplitude global sobre o tema, "novas evidências continuam apontando para um aumento da fome no mundo nos últimos anos após um prolongado declínio. Estima-se que 821 milhões de pessoas - aproximadamente uma em cada nove pessoas no mundo - estão subnutridas" (FAO, IFAD, UNICEF, WFP and WHO, 2018, p. 2), ou seja, apesar dos avanços na redução da fome global durante as duas últimas décadas, a tendência global indica a reversão dos índices. Dessa forma,o presente trabalho justifica-se pelas recentes tendências globais na luta mais antiga da humanidade: a luta contra a fome.

A proposta central aqui é analisar as políticas públicas de Segurança Alimentar e Nutricional brasileiras a partir dos primeiros anos do século XXI, nomeadamente o Programa de Aquisição de Alimentos (PAA), o Programa Nacional de Fortalecimento da Agricultura Familiar (PRONAF) e o Programa Nacional de Fortalecimento da Agricultura Familiar e o Programa Nacional de Alimentação Escolar (PNAE) no estado de São Paulo a partir do perfil socioeconômico de suas 16 Regiões Administrativas (RA).

Para tanto, será realizada uma breve exposição teórica sobre a relação entre intervenções estatais e SAN, além de uma contextualização sobre a conformação do espaço agrário brasileiro e pontuar os principais processos os quais a criação de tais políticas se inseriu.

Com o intuito de avaliar as políticas públicas selecionadas, foi realizado um levantamento de dados secundários sobre as execuções e distribuição entre os anos de 2011 a 2016. os dados referentes ao PAA foram extraídos do Portal de Transparência da Companhia Nacional de Abastecimento (CONAB), enquanto que Aqueles referentes ao PRONAF foram retirados da Base de Dados de Crédito Rural do Banco Central brasileiro e os referentes ao PNAE foram utilizados os dados disponíveis no portal do Fundo Nacional de Desenvolvimento da Educação (FNDE). Relatórios e documentos relacionados às políticas em questão foram utilizados de maneira complementar aos dados secundários.

Para a caracterização do perfil socioeconômico e do nível de desenvolvimento humano das regiões administrativas do estado de São Paulo, foram levantados dados a partir do Atlas de Desenvolvimento Humano mantido pelo Programa das Nações Unidas para o Desenvolvimento (PNUD) e do Instituto Brasileiro de Geografia e Estatística (IBGE), ambos utilizando como base o levantamento censitário de 2010. As informações referentes aos aspectos rurais e, sobretudo, relativos à agricultura familiar dos municípios foram retiradas do Censo Agropecuário de 2006 do IBGE.

Todos os dados secundários foram compilados e sistematizados em planilhas do Microsoft Excel e foram submetidos à processamento por meio do software de análise de dados Rstudio,1 através do qual se produziram gráficos e 
histogramas com o intuito de destacar os resultados obtidos. Foi utilizado ainda o software de georreferenciamento de dados QGIS, utilizando mapas cartográficos obtidos no Portal de Mapas do IBGE na confecção de mapas e cartogramas. Associado à análise dos dados, foram analisados documentos oficiais do governo brasileiro, de instituições especializadas, organismos internacionais e de entidades relevantes, de maneira a alcançar melhor compreensão dos dados.

Não se objetiva aqui uma análise aprofundada acerca de cada programa em específico, mas sim obter um panorama geral do comportamento e funcionamento relativo às ações direcionadas ao cumprimento da SAN e do Direito Humano à Alimentação e, por consequência, promotoras do desenvolvimento humano no Brasil em dado período.

\title{
Intervenção do Estado e Segurança Alimentar Nutricional
}

Para Josué de Castro era preciso admitir a fome enquanto fenômeno social coletivo e multidimensional impelido por fatores diversos - internos e externos às nações. Suas contribuições relativas à alimentação cobriam o amplo espectro que vai da saúde e nutrição até as dimensões socioeconômica, espacial e cultural subjacentes à condição alimentar e nutricional dos indivíduos, grupos sociais e países (CASTRO, 2005).

\begin{abstract}
"ao imperialismo econômico e ao comércio internacional a serviço do mesmo interessava que a produção, a distribuição e o consumo dos produtos alimentares continuassem a se processar indefinidamente como fenômenos exclusivamente econômicos - dirigidos e estimulados dentro dos seus interesses econômicos - e não como fatos intimamente ligados aos interesses da saúde pública”. (CASTRO, 2005, p. 21).
\end{abstract}

De maneira geral, a insegurança alimentar é mais aguda entre as classes sociais mais vulneráveis e com a menor renda, significando um obstáculo ao acesso aos alimentos e à garantia da SAN. Considerando que o crescimento econômico não conduz necessariamente à redução da pobreza e das desigualdades, é necessário, portanto, redistribuir o crescimento da economia considerando que dentre os fatores que influem de maneira mais incisiva para a manifestação da fome e da subnutrição, a classe social e nível de renda constituem alguns dos principais determinantes (CASTRO, 2005; IBGE, 2010; MALUF \& DOS REIS, 2013).

Embora o mercado seja eficiente para alavancar forças produtivas e disseminar formas econômicas, ele não parece operar de maneira efetiva para a geração de bem-estar social, uma vez que constantemente gera externalidades negativas (como o caso do aprofundamento da miséria no campo). Em sociedades de mercado, a falha do Mercado é definida como "uma circunstância em que a busca por interesses privados não leva a um uso eficiente dos recursos da sociedade ou a uma distribuição justa dos bens da sociedade" (WEIMER E VINING, 1999, pp. 41). Contudo, é vital identificar os tipos e as fontes das falhas de mercado nos sistemas alimentares no esforço de desenvolver políticas 
apropriadas para lidar com elas, uma vez que a ação econômica do Estado e as próprias políticas públicas desempenham papel decisivo na criação e consolidação dos sistemas alimentares (ROCHA, 2007).

Enquanto falhas de mercado podem ser geradoras de externalidades negativas, outro argumento que justifica a ação estatal é a incapacidade do livre mercado em gerar bens públicos em quantidade suficiente.

\begin{abstract}
"Bens públicos" é o termo usado para descrever bens caracterizados por duas características: eles não são rivais e não exclusivos. Ser não-rival significa que, uma vez disponíveis, eles podem ser desfrutados simultaneamente por muitas pessoas. Como bens não exclusivos, uma vez disponíveis, é muito difícil impedir que as pessoas os usem, mesmo aqueles que não pagaram por eles. O oposto de bens públicos são "bens privados", que são rivais e exclusivos. Muitas mercadorias não podem ser desfrutadas simultaneamente por muitas pessoas, e os indivíduos podem ser impedidos de usá-las (se, por exemplo, eles não pagarem por sua compra) (ROCHA, 2007, p. 16).
\end{abstract}

Se considerarmos a SAN enquanto um bem público, a lógica do mercado entra em conflito aqui com o Direito Humano à Alimentação Adequada. Apesar dos benefícios gerados à sociedade, o livre mercado não encontra incentivos para sua criação e manutenção, pressupondo, então, a necessidade da ação estatal para a geração de quantidades suficientes deste bem público específico (EECKE, 1999).

Adotar a SAN como um bem público justifica a intervenção do governo em sociedades de mercado. Garantir a SAN consiste em operar a partir de um conjunto de princípios imprescindíveis: DHAA; universalidade; equidade; participação social; sustentabilidade; descentralização e Intersetorialidade. Uma vez que "o enfoque da SAN demanda que sejam considerados os aspectos sociais, culturais e ambientais envolvidos na produção e comercialização dos alimentos, mesmo no contexto de sociedades e economias mais abertas ao exterior" (MALUF \& DOS REIS, 2014, p. 18), para garantir a SAN é necessária a constituição de um Estado Social alicerçado no Direito, (PEREIRA, 1999) capaz de corrigir falhas de mercado e gerar bens públicos.

Compreendida sua importância e profundidade, a responsabilidade de prover a SAN torna-se uma tarefa incontornável dos Estados (MALUF, 2007). É nesse sentido que o conceito de SAN é passível de conversão em um dos eixos ordenadores das estratégias de desenvolvimento de um país, sugerindo formas mais equitativas e sustentáveis de produzir e comercializar os alimentos, questionando o padrão de consumo alimentar e requalificando as ações dirigidas para os grupos sociais mais vulneráveis à fome e à desnutrição. As ações e políticas públicas de SAN participam, portanto, da difícil tarefa de associar dinamismo econômico, promoção de equidade social e melhoria sustentável da qualidade de vida. (MALUF \& DOS REIS, 2014 p. 20). 


\section{Reformas Liberalizantes e a Reorientação do Desenvolvimento Rural Baseado na Agricultura Familiar (1990-2003)}

Durante parte da década de 1990, observou-se no Brasil a disputa entre dois projetos contraditórios no campo: um neoliberal voltado ao agronegócio estabelecido nas décadas anteriores e um segundo democratizante, que propunha um novo modelo de desenvolvimento rural baseado na agricultura familiar.

As mudanças trazidas pelo conjunto de crises e medidas de ajustamento interno observadas na década anterior, somadas às crescentes pressões do Fundo Monetário Internacional (FMI), promovem a liberalização da economia por meio de privatizações e reformas administrativas, que culminaram na extinção de órgãos públicos regulatórios visando maior margem fiscal ao Governo Federal. O resultado foi uma redução significativa de gastos federais relacionados à política agrícola e agrária contando que a importação de alimentos poderia suprir as lacunas relativas à essas produção nacional deixadas pelo desinvestimento público (BACARRIN, 2011).

Tais proposições técnicas somadas ao acirramento das tensões fundiárias nos anos de 1995 e 1996¹, e à mobilização social de acadêmicos, representações sociais de trabalhadores e agricultores familiares e em torno da questão agrária conduz à criação do Ministério de Desenvolvimento Agrário (MDA) em 1996 e a criação de uma linha de crédito diferenciada voltada à agricultura familiar: o Programa Nacional de Fortalecimento da Agricultura Familiar (PRONAF) foi estabelecido no mesmo ano, inaugurando um novo capítulo para o desenvolvimento rural brasileiro, onde a agricultura familiar progressivamente começa a ocupar posição central.

Assentado na estratégia de estabelecer parcerias entre as esferas municipais, estaduais e federal de poder, o PRONAF é criado essencialmente com "a finalidade de promover o desenvolvimento sustentável do segmento rural constituído pelos agricultores familiares, de modo a propiciar-lhes o aumento da capacidade produtiva, a geração de empregos e a melhoria de renda" (Brasil, 1996) para tanto "buscava corrigir as desigualdades do espaço rural brasileiro e a má distribuição de crédito entre os agentes econômicos" (OLIVEIRA, 2015) levando transferências para regiões não originalmente contempladas pelas linhas de crédito oferecidas no período da modernização agrícola.

\footnotetext{
“[...] as transformações de perspectivas em relação à produção familiar ocorreram em consequência das pressões sociais sobre o Governo Federal, especialmente entre 1960 e 1990. Posteriormente, a partir de 1990, o Estado estrutura de maneira significativa o processo de construção de políticas públicas para agricultura familiar com objetivo de valorizar esse segmento produtivo. Nesta perspectiva, a agricultura familiar surge como elemento mediador para um espaço rural mais equitativo." (Ibid, 2015, p. 35)
}

\footnotetext{
${ }^{1}$ Dentro os episódios mais trágicos citam-se os massacres de Eldorado dos Carajás (PA) e Corumbiara (RO) onde, em confronto com a Polícia Militar, dezenas de trabalhadores sem terra foram assassinados.
} 
A institucionalização dos conselhos nas três esferas é determinante para a criação do Gabinete Extraordinário da Política Fundiária em 1997, que se converte em Ministério do Desenvolvimento Agrário em 1999 absorvendo o PRONAF e criando a Secretaria Nacional da Agricultura Familiar (SAF).

Apesar do significativo avanço no estabelecimento e operacionalização de políticas públicas voltadas a este segmento produtivo, os resultados no que tange à SAN demonstram-se incipientes. É constatado que que o crédito não chega de maneira proporcional à todas as regiões do país, sendo absorvido com maior facilidade pela região $\mathrm{Sul}^{2}$, explicado pelo maior nível de organização de seus produtores familiares, maior integração aos mercados e pela tradição da luta do crédito (MATTEI, 2007).

\section{O Programa Fome Zero e a Consolidação da Agricultura Familiar no Novo Modelo de Desenvolvimento Brasileiro (2003-2016)}

A partir de 2003, com a chegada do Partido dos Trabalhadores (PT) ao poder na figura de Luís Inácio Lula da Silva, o tema da fome torna-se central na política do novo governo, que se pautará nos anos seguintes pelos esforços na conjugação das agendas social e econômica. Nas palavras do próprio presidente "Se, ao final do meu mandato, cada brasileiro puder se alimentar três vezes ao dia, terei realizado a missão de minha vida" (trecho do primeiro discurso do Presidente eleito, em 20/10/2002).

O processo de formulação da Política Nacional de Segurança Alimentar e Nutricional3 no Brasil demandou a organização de uma base teórica capaz de conjugar categorias chave para o debate político: Estado, sociedade civil e políticas públicas (PINHEIRO, 2009, p.28). A adoção do conceito atual de Segurança Alimentar e Nutricional só foi possível mediante um processo histórico, político e conjuntural na América Latina e mais especificamente no Brasil.

Como o problema da fome no Brasil não se devia à falta de disponibilidade de alimento e sim à dificuldade de acesso, a concepção empregada pelo governo brasileiro partiu do pressuposto que a solução do problema da fome passava pelo combate à miséria-e à desigualdade social e a efetividade desta passava pela vinculação do combate à fome à construção de uma política de SAN que levasse em conta o direito humano à alimentação e a soberania alimentar do Brasil. $\mathrm{O}$

\footnotetext{
${ }^{2}$ A região Sul representa $22 \%$ dos agricultores familiares do país, mas concentra os maiores aportes de do PRONAF, chegando a $57 \%$ do montante total em 1999. Apesar da região Nordeste representar $48 \%$ dos agricultores familiares, no mesmo ano foram destinados somente $17 \%$ dos recursos do programa tendo atingido 26\%, a maior percentagem, no ano de 2006 (Pereira et al., 2014, pp. 349).

3 Instaurada pelo Decreto No 7.272 de 25 de Agosto de 2010, dispõe sobre a gestão, mecanismos de financiamento, monitoramento e avaliação, no âmbito do Sistema Nacional de Segurança Alimentar e Nutricional - SISAN, e estabelece os parâmetros para a elaboração do Plano Nacional de Segurança Alimentar e Nutricional.
} 
Direito Humano à Alimentação Adequada é realizado quando cada homem, mulher e criança tem acesso físico e econômico, ininterruptamente, à alimentação adequada ou aos meios para sua obtenção (FAO, 2015).

No centro da estratégia de combate à pobreza figurava o Programa Fome Zero (PFZ), que promoveu intensa articulação institucional e progressiva integração de uma diversidade de programas anteriormente dispersos. Considerando a sua capacidade de resposta às políticas públicas (FAO, 2015) e a suposição da existência de sinergias entre os programas e ações públicas, (OLIVEIRA, 2015) o segmento da agricultura familiar teve papel de destaque no PFZ desde a sua concepção.

Contudo, José Graziano da Silva (2009) salienta que para que o PFZ pudesse começar a gerar resultados, um processo de fortalecimento, construção e reconstrução de instituições e instrumentos de promoção do desenvolvimento da agricultura familiar deveria ser conduzido. Nesse conjunto de ações é recriado o Conselho Nacional de Segurança Alimentar e Nutricional (CONSEA)4, garantindo o componente de participação social do programa e reforçando o compromisso do governo com o projeto democratizante do rural, além de sua manifestação por meio da construção de um modelo alternativo de desenvolvimento rural baseado na agricultura familiar.

Outro ponto de destaque foi a promulgação da Lei Nacional de Segurança Alimentar e Nutricional do Brasil (Lei ${ }^{0}$ 11.346, de setembro de 2006), que define segurança alimentar e nutricional como "a realização do direito de todos ao acesso regular e permanente a alimentos suficientes de boa qualidade, sem comprometer o acesso a outras necessidades básicas e com base em práticas alimentares que promovem a saúde, respeitam a diversidade cultural e são ambiental, cultural, economicamente e socialmente sustentáveis "(BRASIL, 2006).

É no bojo do PFZ e proveniente de intensa articulação do CONSEA, que o Programa de Aquisição de Alimentos da Agricultura Familiar (PAA) é criado. O PAA parece complementar o PRONAF, na medida em que atende com maior intensidade justamente aqueles agricultores com maiores dificuldades de acesso ao programa de crédito rural (OLIVEIRA, 2012), elevando a incidência das políticas públicas nas áreas originalmente marginalizadas pela modernização da agricultura e que apresentavam dificuldades de acesso às mesmas. De um modo geral, o PAA busca contribuir para o aumento de renda das unidades da agricultura familiar, por meio da compra institucional de alimentos de origem agropecuária por preços acima dos de mercado e distribuindo-os à grupos sociais suscetíveis à condição de insegurança alimentar, entre eles asilos, orfanatos,

\footnotetext{
${ }_{4}$ É importante destacar que o modelo do CONSEA é celebrado mundialmente, uma vez que se configura um espaço de diálogo entre representantes de vários setores da sociedade e governo. Tem sido notavelmente bem-sucedido em promover uma estratégia intersetorial em face a fenômenos multidimensionais, como são os casos da fome e da má nutrição por meio da inclusão de reivindicações, experiências e propostas da sociedade civil na formulação e aprimoramento de políticas públicas relacionadas à realização dos direitos humanos para uma nutrição adequada, sendo, inclusive, recomendado a sua aplicação pelo Conselho Mundial de Alimentação da FAO.
} 
creches e escolas públicas (Modalidade de Compra com Doação Simultânea). O Programa prevê também a formação de estoques estratégicos de alimentos (Modalidade de Formação de Estoques) e o facilitamento do processo de comercialização no âmbito local (OLIVEIRA, 2015).

Seguindo o processo de ampliação das políticas voltadas à agricultura familiar e, com a vocação de integrar também o setor da educação criou-se o Programa Nacional de Alimentação Escolar (PNAE) por meio da Lei 11.947, de 2009. Junto ao PAA, o PNAE busca o estabelecimento de mecanismos de comercialização para os produtos originários da agricultura familiar, alavancando processos de agregação de valor à produção. Tal lei definiu que pelo menos $30 \%$ dos recursos repassados pelo governo para a merenda escolar devem ser utilizados na aquisição de gêneros alimentícios advindos da agricultura familiar, com prioridade aos assentamentos de reforma agrária, comunidades tradicionais, quilombolas etc." (MATTEI, 2017, p. 81).

Gerenciado pelo Fundo Nacional de Desenvolvimento da Educação (FNDE), o PNAE opera a partir da transferência, em caráter suplementar, de recursos financeiros aos estados, ao Distrito Federal e aos municípios, para garantir, parcialmente, as necessidades nutricionais dos alunos (FNDE, 2015). Dessa forma, "estabeleceu-se um elo mais forte entre essa política e o sistema familiar de produção.

Baseado no conceito de que era dever do governo garantir que todos os brasileiros pudessem desfrutar do direito à alimentação adequada visando o desenvolvimento de mercados e o fortalecimento do setor privado, com ênfase nos pequenos empreendedores, Lula colocou a erradicação da fome e a redução da pobreza no centro do desenvolvimento do Brasil, engajando todos os ministérios setoriais e níveis de governo, bem como a sociedade brasileira em geral, em um esforço massivo e concertado para trabalhar nessa agenda (CABRAL, 2013).

Uma política nacional integrada de SAN foi criada, sendo sustentada por um novo quadro jurídico e institucional e "é a partir dessa ampla e rica experiência, em conjunto com a implementação dos programas Fome Zero, Bolsa Família e Brasil sem Miséria em todo o território no período de 2003-2013, e outras iniciativas que, em conjunto, resultaram na saída do país do mapa da Fome em 2014." (FAO, 2016).

\section{Análise das políticas públicas voltada à agricultura familiar no estado de São Paulo (PRONAF, PAA, PNAE)}

\section{O perfil socioeconômico e agrário do estado de São Paulo}

Para efeito de análise no estado de São Paulo, utilizamos aqui a divisão proposta pelo Instituto de Economia Agrícola do Estado de São Paulo (IEA), onde os 645 municípios são agrupados em 15 regiões mais a região metropolitana de São Paulo. A partir deste agrupamento, a tabela 1 apresenta a distribuição das populações entre as RAs. Nota-se que a população do estado se concentra com 
grande intensidade nas áreas metropolitanas como São Paulo, que reúne quase a metade da população $(47,7 \%)$ e Campinas (15,1\%). Somando juntas $71,7 \%$ do PIB do estado, indica uma distribuição econômica e demográfica extremamente desiguais. Inversamente, as RAs que apresentam as menores densidades demográficas são as que possuem a maior porcentagem relativa de sua população vivendo nas áreas rurais, como é o caso de Registro, onde $28,6 \%$ de sua população habita o espaço rural, seguido de Itapeva $(23,9 \%)$ e Presidente Prudente $(11,2 \%)$, que, juntas, concentram pequena parcela relativa do PIB estadual $(2,3 \%)$.

Tabela 1 - População e População Rural por RAs em Ordem Alfabética.

\begin{tabular}{|c|c|c|c|c|c|c|}
\hline \multirow{2}{*}{$\begin{array}{c}\text { Região } \\
\text { Administrativa }\end{array}$} & \multirow{2}{*}{$\underset{\text { os }}{\text { No }}$} & \multicolumn{2}{|c|}{ População Total } & \multicolumn{2}{|c|}{ População Rural } & \multirow{2}{*}{$\begin{array}{l}\text { PIB (em } \\
\text { mil reais) }\end{array}$} \\
\hline & & $\begin{array}{c}\text { Habitante } \\
s\end{array}$ & \% SP & $\begin{array}{l}\text { Habitant } \\
\text { es }\end{array}$ & $\%$ & \\
\hline Araçatuba & 43 & 735965 & $1,8 \%$ & 57923 & $7,9 \%$ & $25 \cdot 755 \cdot 778$ \\
\hline Barretos & 19 & 419587 & $1,0 \%$ & 22661 & $5,4 \%$ & 18.000.908 \\
\hline Bauru & 39 & 1053258 & $2,6 \%$ & 59271 & $5,6 \%$ & 41.403 .853 \\
\hline Campinas & 90 & 6249185 & $15,1 \%$ & 318643 & $5,1 \%$ & 353.265 .004 \\
\hline Central & 26 & 952269 & $2,3 \%$ & 47291 & $5,0 \%$ & 35.854 .066 \\
\hline Franca & 23 & 706283 & $1,7 \%$ & 38019 & $5,4 \%$ & 23.674 .279 \\
\hline Grande São Paulo & 39 & 19683975 & $47,7 \%$ & 225087 & $1,1 \%$ & $\begin{array}{c}1.107 .867 .63 \\
6\end{array}$ \\
\hline Itapeva & 32 & 514302 & $1,2 \%$ & 123033 & $23,9 \%$ & 12.524 .039 \\
\hline Marília & 51 & 940814 & $2,3 \%$ & 72819 & $7,7 \%$ & 29.698 .803 \\
\hline Presidente Prudente & 53 & 833530 & $2,0 \%$ & 93239 & $11,2 \%$ & 26.590 .235 \\
\hline Registro & 14 & 269267 & $0,7 \%$ & 76993 & $28,6 \%$ & $7.007 \cdot 517$ \\
\hline Ribeirão Preto & 25 & 1247761 & $3,0 \%$ & 30985 & $2,5 \%$ & $51.615 \cdot 732$ \\
\hline Santos & 9 & 1664136 & $4,0 \%$ & 3461 & $0,2 \%$ & 63.951 .257 \\
\hline São José dos Campos & 96 & 1437549 & $3,5 \%$ & 118148 & $8,2 \%$ & 49.546 .993 \\
\hline São José do Rio Preto & 39 & 2264594 & $5,5 \%$ & 133298 & $5,9 \%$ & 98.115 .179 \\
\hline Sorocaba & 47 & 2289724 & $5,5 \%$ & 256077 & $11,2 \%$ & 93.133 .653 \\
\hline $\begin{array}{c}\text { Estado de São } \\
\text { Paulo }\end{array}$ & 645 & 41262199 & $\begin{array}{c}100,0 \\
\%\end{array}$ & 1676948 & $\begin{array}{c}100,0 \\
\%\end{array}$ & $\begin{array}{c}\text { 2.038.004. } \\
931\end{array}$ \\
\hline
\end{tabular}

Fonte: Elaborado pelo autor com base nos dados do censo demográfico de 2010 (IBGE)

Comparando a distribuição do PIB per capita no estado de São Paulo, constata-se que a diferenciação entre as RAs se estende além da distribuição demográfica, revelando uma discrepância de 2 vezes o valor entre seus extremos, conforme indica o gráfico 1 . 
Gráfico 1 - PIB Per Capta por RA em ordem Crescente em Reais.

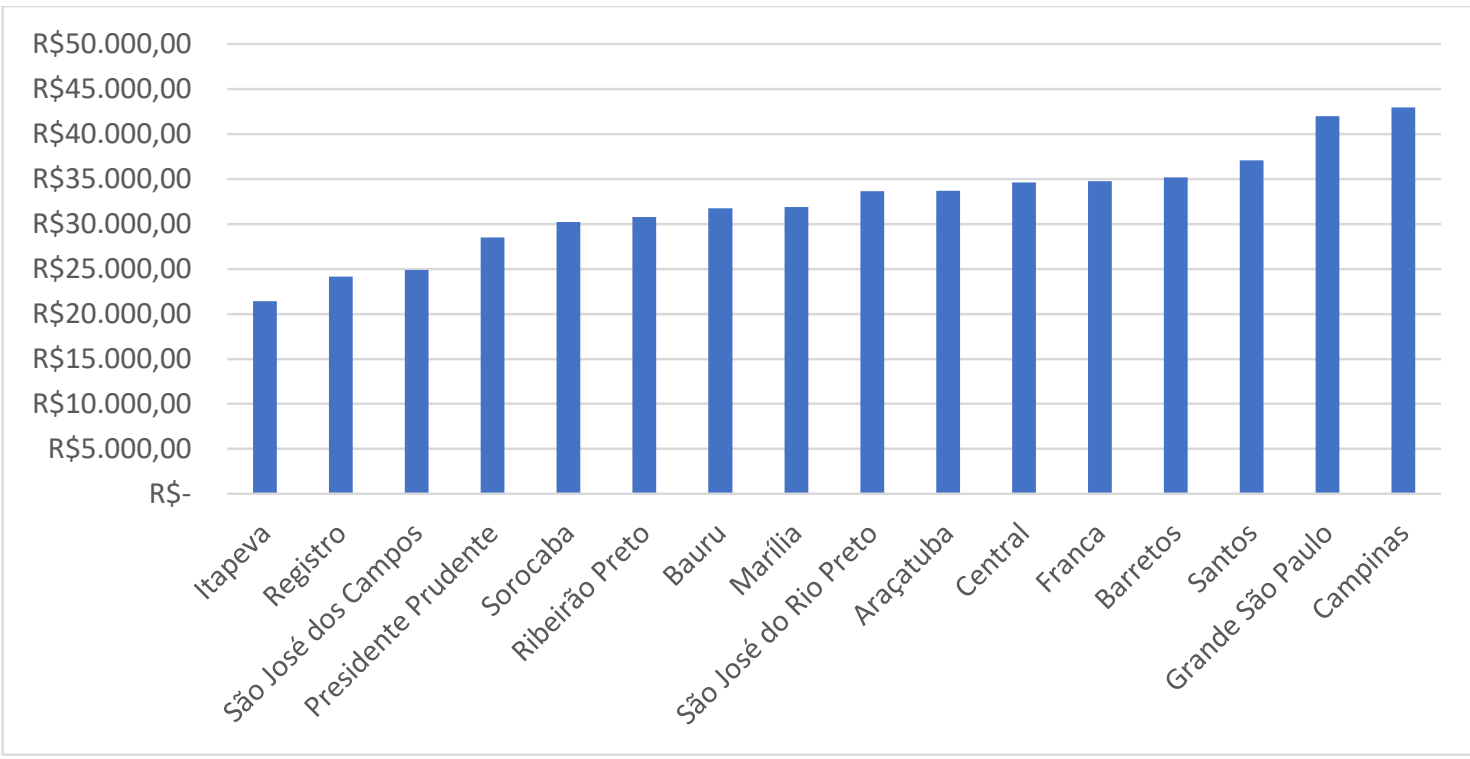

Fonte: Elaborado pelo autor com base nos dados do IBGE (2016)

A tabela 2 apresenta indicadores socioeconômicos que reforçam a lógica de que os maiores índices de urbanização e desenvolvimento econômico do estado carregam consigo outros aspectos além do econômico, como indica os elevados Índices de Desenvolvimento Humano Municipal (IDHM) e reduzidas percentagens de extrema pobreza, pobreza e vulnerabilidade. A lógica se inverte quando se trata daquelas RAs com maior expressividade agrícola, evidenciando uma patente relação do mundo rural com a pobreza multidimensional no estado.

Tabela 2 - Indicadores Socioeconômicos por RAs em Ordem Alfabética.

\begin{tabular}{|c|c|c|c|c|c|c|}
\hline $\begin{array}{c}\text { Região } \\
\text { Administrativa }\end{array}$ & $\begin{array}{l}\text { Ocup. Setor } \\
\text { Agropecuár } \\
\text { io }\end{array}$ & $\begin{array}{l}\text { \% Ext. } \\
\text { Pobres }\end{array}$ & $\begin{array}{c}\% \\
\text { Pobres }\end{array}$ & $\begin{array}{c}\text { \% em } \\
\underset{\text { de }}{\text { Vulnerabilida }}\end{array}$ & IDHM & $\begin{array}{l}\text { IDHM } \\
\text { Renda }\end{array}$ \\
\hline Araçatuba & 22,76 & 1,25 & 4,34 & 17,66 & 0,740 & 0,712 \\
\hline Barretos & 28,64 & 0,71 & 3,46 & 15,69 & 0,741 & 0,722 \\
\hline Bauru & 22,75 & 1,13 & 4,85 & 18,26 & 0,738 & 0,718 \\
\hline Campinas & 13,77 & 0,90 & 3,82 & 15,22 & 0,754 & 0,746 \\
\hline Central & 21,92 & 1,17 & 4,60 & 16,34 & 0,745 & 0,722 \\
\hline Franca & 20,64 & 1,19 & 5,16 & 19,64 & 0,738 & 0,724 \\
\hline Grande São Paulo & 3,35 & 1,74 & 6,40 & 21,26 & 0,760 & 0,737 \\
\hline Itapeva & 35,01 & 4,98 & 16,27 & 39,81 & 0,695 & 0,658 \\
\hline Marília & 25,48 & 1,45 & 6,14 & 22,78 & 0,737 & 0,704 \\
\hline Presidente Prudente & 20,89 & 1,75 & 6,32 & 22,95 & 0,736 & 0,700 \\
\hline Registro & 23,75 & 5,12 & 17,17 & 39,99 & 0,703 & 0,665 \\
\hline Ribeirão Preto & 16,24 & 1,18 & 4,62 & 17,64 & 0,741 & 0,727 \\
\hline Santos & 1,41 & 1,98 & 7,06 & 21,53 & 0,759 & 0,742 \\
\hline
\end{tabular}




\begin{tabular}{c|c|c|c|c|c|c} 
São José do Rio Preto & 23,54 & 0,84 & 3,44 & 15,32 & 0,743 & 0,718 \\
São José dos Campos & 12,20 & 2,52 & 9,80 & 28,39 & 0,735 & 0,708 \\
Sorocaba & 17,82 & 1,56 & 6,14 & 21,04 & 0,733 & 0,717 \\
\hline Estado de SP & $\mathbf{2 1 , 4 0 5}$ & $\mathbf{1 , 3 5}$ & $\mathbf{5 , 6 5}$ & $\mathbf{2 0 , 3 4}$ & $\mathbf{0 , 7 3 9}$ & $\mathbf{0 , 7 1 8}$ \\
\hline
\end{tabular}

Passando especificamente à análise da presença e características da agricultura familiar no estado, constata-se que, como demonstrado na tabela 3, a área ocupada pela agricultura familiar representa somente $14,7 \%$ do total da área ocupada pela agricultura. Contudo, o número de estabelecimentos soma $66,3 \%$ do total de estabelecimentos agrários. Novamente, constata-se forte presença da agricultura familiar nas regiões de Itapeva $(72,6 \%)$, Registro $(68,4 \%)$ e Presidente Prudente (70,1\%), indicando uma relação da causa da pobreza nestas RAs e as dificuldades impostas a este modelo de agricultura durante o período da modernização conservadora no campo. Neste período, os pequenos agricultores não encontravam condições suficientes para competir no livre mercado com os complexos agroindustriais, o que resulta no aprofundando do descompasso em termos de desenvolvimento com regiões mais urbanizadas.

Tabela 3 - Agricultura Familiar e Não Familiar por RA em Ordem Alfabética

\begin{tabular}{|c|c|c|c|c|c|c|c|c|}
\hline \multirow{2}{*}{$\begin{array}{c}\text { Região } \\
\text { Administrativa }\end{array}$} & \multicolumn{2}{|c|}{$\begin{array}{c}\text { Estab. agricultura } \\
\text { familiar }\end{array}$} & \multicolumn{2}{|c|}{$\begin{array}{c}\text { Área } \\
\text { agricultura } \\
\text { familiar }\end{array}$} & \multicolumn{2}{|c|}{$\begin{array}{c}\text { Estab. } \\
\text { agricultura } \\
\text { não familiar }\end{array}$} & \multicolumn{2}{|c|}{$\begin{array}{c}\text { Área } \\
\text { agricultura } \\
\text { não familiar }\end{array}$} \\
\hline & Número & \% Total & hectare & $\begin{array}{c}\% \\
\text { Total }\end{array}$ & Número & $\begin{array}{c}\% \\
\text { Tota } \\
1\end{array}$ & hectare & $\begin{array}{c}\% \\
\text { Total }\end{array}$ \\
\hline Araçatuba & 11177 & $71,2 \%$ & 244824 & $17,4 \%$ & 4527 & $\begin{array}{c}28,8 \\
\%\end{array}$ & 1162934 & $\begin{array}{c}82,6 \\
\%\end{array}$ \\
\hline Barretos & 3236 & $51,7 \%$ & 59708 & $8,6 \%$ & 3028 & $\begin{array}{c}48,3 \\
\%\end{array}$ & 634642 & $\begin{array}{c}91,4 \\
\%\end{array}$ \\
\hline Bauru & 7415 & $61,7 \%$ & 122844 & $9,3 \%$ & 4596 & $\begin{array}{c}38,3 \\
\%\end{array}$ & 1191803 & $\begin{array}{c}90,7 \\
\%\end{array}$ \\
\hline Campinas & 20449 & $65,4 \%$ & 241228 & $14,7 \%$ & 10810 & $\begin{array}{c}34,6 \\
\%\end{array}$ & $\begin{array}{c}139809 \\
6\end{array}$ & $\begin{array}{c}85,3 \\
\%\end{array}$ \\
\hline Central & 4389 & $55,3 \%$ & 74791 & $10,1 \%$ & 3546 & $\begin{array}{c}44,7 \\
\%\end{array}$ & 665997 & $\begin{array}{c}89,9 \\
\%\end{array}$ \\
\hline Franca & 3987 & $54,3 \%$ & 71278 & $8,7 \%$ & 3361 & $\begin{array}{c}45,7 \\
\%\end{array}$ & 743783 & $\begin{array}{c}91,3 \\
\%\end{array}$ \\
\hline Grande São Paulo & 2959 & $68,0 \%$ & 17150 & $\begin{array}{c}14,4 \\
\%\end{array}$ & 1390 & $\begin{array}{c}32,0 \\
\%\end{array}$ & 101692 & $\begin{array}{c}85,6 \\
\%\end{array}$ \\
\hline Itapeva & 12389 & $72,6 \%$ & 189193 & $\begin{array}{l}15,0 \\
\%\end{array}$ & 4680 & $\begin{array}{c}27,4 \\
\%\end{array}$ & $\begin{array}{c}107429 \\
7\end{array}$ & $\begin{array}{c}85,0 \\
\%\end{array}$ \\
\hline Marília & 11187 & $64,7 \%$ & 203786 & $13,5 \%$ & 6110 & $\begin{array}{c}35,3 \\
\%\end{array}$ & $\begin{array}{c}130447 \\
3\end{array}$ & $\begin{array}{c}86,5 \\
\%\end{array}$ \\
\hline Presidente Prudente & 18115 & $70,1 \%$ & 344259 & $\begin{array}{c}16,8 \\
\%\end{array}$ & 7711 & $\begin{array}{c}29,9 \\
\%\end{array}$ & $\begin{array}{c}170949 \\
4\end{array}$ & $\begin{array}{c}83,2 \\
\%\end{array}$ \\
\hline Registro & 4111 & $68,4 \%$ & 56591 & $\begin{array}{c}14,0 \\
\%\end{array}$ & 1903 & $\begin{array}{c}31,6 \\
\%\end{array}$ & 348505 & $\begin{array}{c}86,0 \\
\%\end{array}$ \\
\hline
\end{tabular}




\begin{tabular}{|c|c|c|c|c|c|c|c|c|}
\hline Ribeirão Preto & 4465 & $59,5 \%$ & 66363 & $6,5 \%$ & 3041 & $\begin{array}{c}40,5 \\
\%\end{array}$ & 950916 & $\begin{array}{c}93,5 \\
\%\end{array}$ \\
\hline Santos & 145 & $53,9 \%$ & 1926 & $9,7 \%$ & 124 & $\begin{array}{c}46,1 \\
\%\end{array}$ & 17972 & $\begin{array}{c}90,3 \\
\%\end{array}$ \\
\hline São José dos Campos & 23110 & $67,4 \%$ & 456725 & $\begin{array}{c}23,5 \\
\%\end{array}$ & 11197 & $\begin{array}{c}32,6 \\
\%\end{array}$ & $\begin{array}{c}148583 \\
6\end{array}$ & $\begin{array}{c}76,5 \\
\%\end{array}$ \\
\hline São José do Rio Preto & 9128 & $69,8 \%$ & 169684 & $\begin{array}{c}22,9 \\
\%\end{array}$ & 3941 & $\begin{array}{c}30,2 \\
\%\end{array}$ & 572705 & $\begin{array}{c}77,1 \\
\%\end{array}$ \\
\hline Sorocaba & 14638 & $68,4 \%$ & 179918 & $\begin{array}{c}14,2 \\
\%\end{array}$ & 6757 & $\begin{array}{c}31,6 \\
\%\end{array}$ & $\begin{array}{c}109023 \\
2\end{array}$ & $\begin{array}{c}85,8 \\
\%\end{array}$ \\
\hline $\begin{array}{c}\text { Estado de São } \\
\text { Paulo }\end{array}$ & 150900 & $66,3 \%$ & $\begin{array}{c}25002 \\
68\end{array}$ & $\begin{array}{c}14,7 \\
\%\end{array}$ & 76722 & $\begin{array}{c}\mathbf{3 3 , 7} \\
\%\end{array}$ & $\begin{array}{c}144533 \\
77\end{array}$ & $\begin{array}{c}\mathbf{8 5 , 3} \\
\%\end{array}$ \\
\hline
\end{tabular}

Fonte: Elaborado pelo autor com base nos dados do censo agropecuário (IBGE, 2006)

Constata-se, portanto, que as regiões menos desenvolvidas do estado são também as que portam uma maior expressividade da agricultura familiar inferindo a existência de condições desfavoráveis à geração de renda e à subsistência desse modelo de produção agrícola que, por sua vez, põe ênfase na diversidade produtiva e contribui significativamente para a construção de sistemas alimentares mais robustos e dinâmicos em termos de SAN enquanto que, se comparados ao modelo não-familiar caracterizado no Brasil pela monocultura, prioriza latifúndios e a produção para exportação.

A extrema pobreza é descrita como "uma condição caracterizada por severa privação de necessidades humanas básicas, incluindo alimentos, água potável, instalações sanitárias, saúde, abrigo, educação e informação." (UNITED NATIONS, 1995, pp. 19). Dessa maneira, se somarmos as condições socioeconômicas às condições desfavoráveis à agricultura familiar, em detrimento do modelo não-familiar, os produtores familiares que habitam as RAs apontadas anteriormente estão duplamente mais vulneráveis à situação de insegurança alimentar. Essa causalidade, que compromete significativamente o acesso a alimentos de qualidade, demonstra a necessidade da intervenção estatal no formato de políticas públicas focalizadas neste segmento, com o intuito de construir e fortalecer sistemas alimentares de SAN.

\section{Comportamento do PAA, PNAE e PRONAF}

Uma vez identificadas que as RAs que concentram os menores níveis de desenvolvimento são aquelas que coincidem com os menores níveis de urbanização e densidade demográfica e com forte presença da agricultura familiar, passamos à análise das políticas públicas específicas, com o intuito de avaliar sua incidência nessas áreas. Buscou-se compreender alguns fatores que influenciam a alocação dos recursos e modulam o comportamento de cada política separadamente e em conjunto. Optou-se por usar a média anual ao invés da soma dos montantes de cada programa, uma vez que os dados referentes à 
execução do PAA não estavam disponíveis para os anos anteriores a 2013, impossibilitando uma comparação relativa à quantidade de recursos.

Dos programas analisados, o PAA possui menor alcance em termos de municípios atendidos, apresentando uma média de 78 municípios atendidos ao ano (Tabela 3). Contudo, a incidência do programa é focalizada nas regiões socioeconomicamente mais vulneráveis e que, por conseguinte, sofrem privações mais severas em termos de SAN, conforme pode ser observado no mapa 3.

Tabela 3 - Relação Recursos e Alcance do PAA, PRONAF e PNAE no Estado de SP.

\begin{tabular}{c|ccc} 
Programa & $\begin{array}{c}\text { Média No municípios } \\
\text { / Ano }\end{array}$ & Média Valor Anual & Valor / Município \\
\hline PRONAF & 599 & $\mathrm{R} \$ 819.626 .537,69$ & $\mathrm{R} \$ 1.368 .324,77$ \\
PNAE & 400 & $\mathrm{R} \$ 82.770 .063,35$ & $\mathrm{R} \$ 206.925,16$ \\
PAA & 78 & $\mathrm{R} \$ 51.574 .691,98$ & $\mathrm{R} \$ 661.214,00$
\end{tabular}

Mapa 3 - Distribuição do PAA

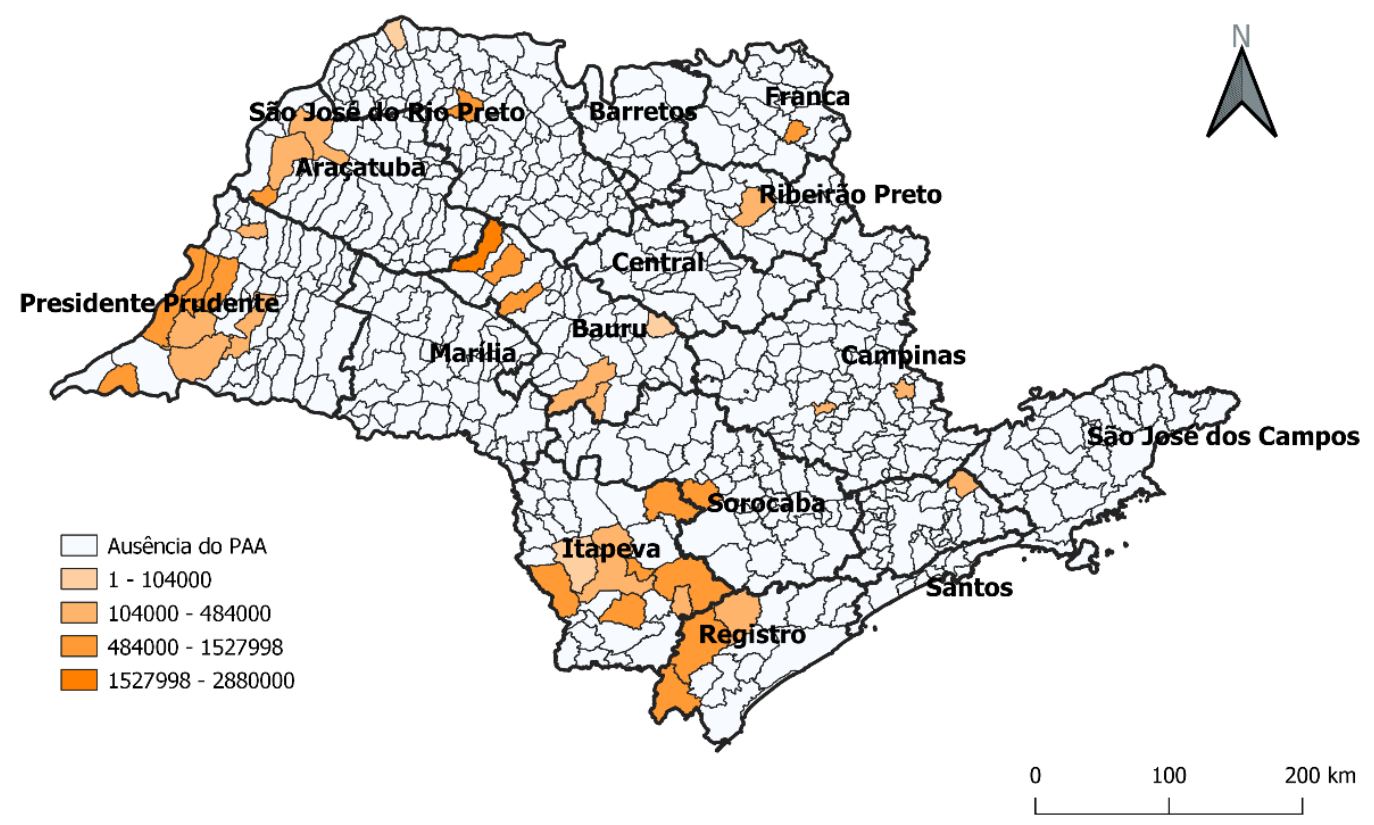

Fonte: Elaborado pelo autor com base nos dados da Companhia Nacional de Abastecimento (CONAB 2016) 
Apresentando uma alta taxa de eficiência, em torno de 93,3\%5, o Gráfico 3 ressalta a influência das características socioeconômicas das RAs descritas anteriormente na alocação do PAA. Operando Sistemas Públicos descentralizados de soberania alimentar, (Produção - Comercialização Consumo), além de integrar políticas de desenvolvimento agrícola e social, o Programa demonstra cumprir com seu objetivo formal de atuar como um instrumento de redução da pobreza e de promoção da SAN. É bem sucedido, portanto, em focalizar não somente os agricultores familiares, mas também populações em situação de insegurança alimentar e em vulnerabilidade social.

Gráfico 3 - PAA Montante Formalizado e Executado por Região em Ordem Crescente de Execução Financeira (2013-2016)

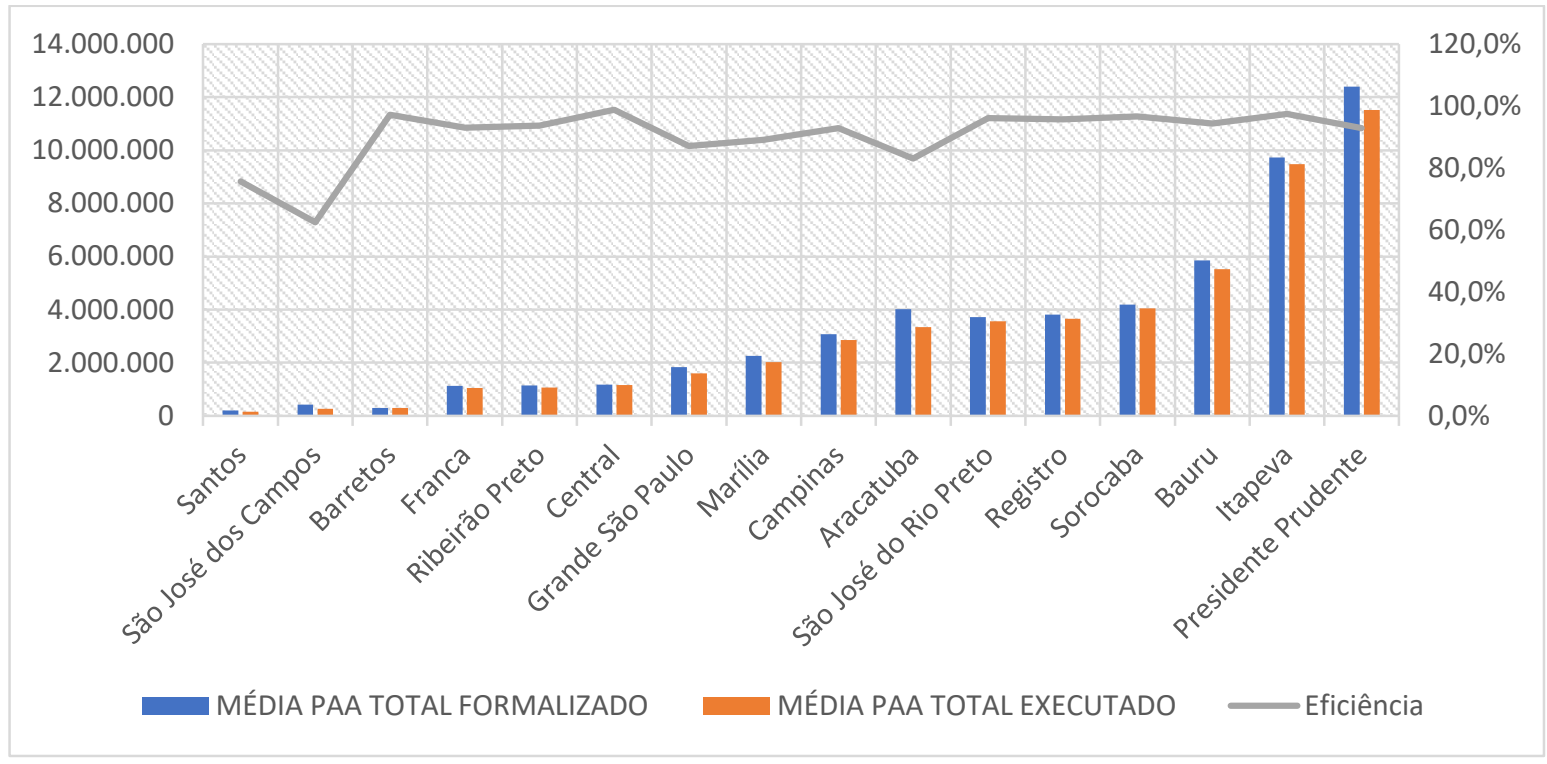

Fonte: Elaborado pelo autor com base nos dados da Companhia Nacional de Abastecimento (CONAB, 2016)

Apesar de seu componente significativo para a agricultura familiar, a alocação dos recursos do PNAE acompanha o número de alunos inscritos na rede pública de ensino, que o Programa apresenta alcance mais uniforme em termos de municípios atendidos (mapa 4) e, naturalmente, sua maior e presença se dá nas RAs de maiores níveis de urbanização e maiores densidades demográficas, como a região metropolitana de São Paulo e os municípios de Sorocaba e Campinas (Gráfico 4).

Ainda que com uma eficiência significativamente menor que a do PAA (uma média de 17,4\%), os recursos formalizados do FNDE para o PNAE apresentam uma soma comparativamente 10 vezes maior à do PAA, como um instrumento fundamental para a abertura e manutenção de um mercado

\footnotetext{
$5 \mathrm{O}$ distanciamento entre a formalização e a execução financeira do PAA se deve a importantes limites em relação aos produtos e organização dos agricultores familiares. No entanto, a tendência que se verifica é de que haja uma aproximação desses valores de disponibilidade financeira e execução orçamentária, considerando os crescentes níveis de organização dos agricultores familiares (Grupo Gestor do PAA, 2011)
} 
institucional para a agricultura familiar e apresentando uma complementaridade importante com este último.

\section{Gráfico 4 - Média PNAE Transferido X Executado por RA em Ordem Crescente de Execução Financeira (2011-2016)}

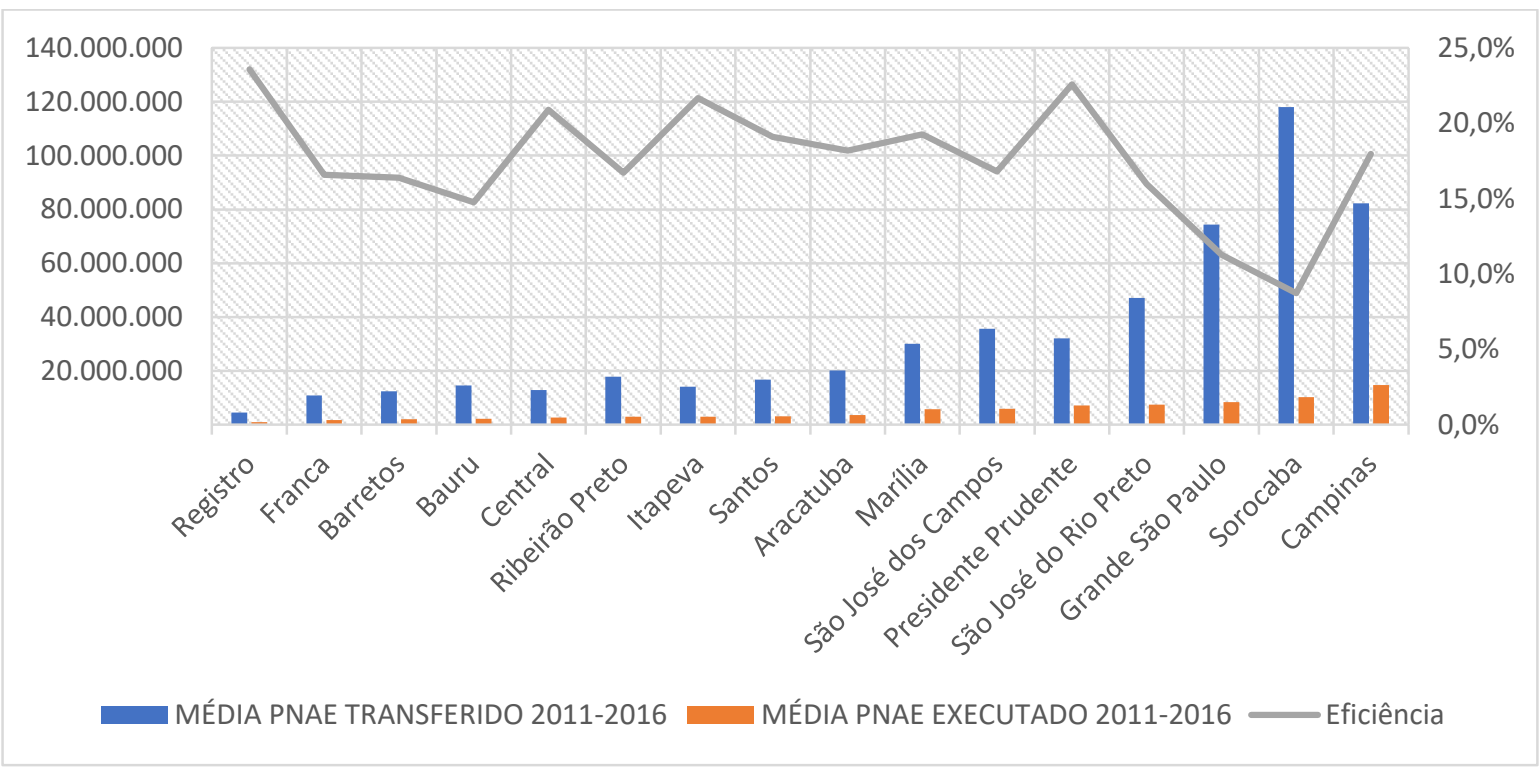

Fonte: Elaborado pelo autor com base nos dados do Fundo Nacional de Desenvolvimento da Educação (FNDE)

Diferente do PAA, o PNAE e o PRONAF atendem um maior número de municípios no estado, e se distribuem de maneira mais uniforme, como demonstram os mapas 4 e 5 .

Mapa 4 - Distribuição do PNAE.

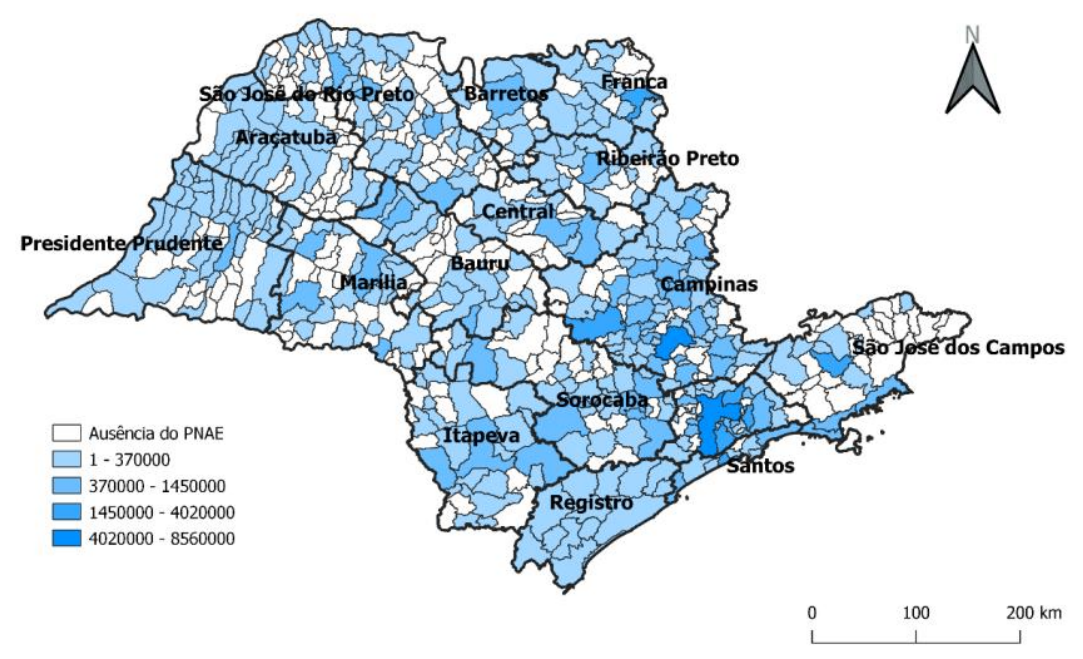

OLIVEIRA, Jonatan Alexandre de; DONATO, Fábio. Desenvolvimento humano e segurança alimentar e nutricional: uma análise das políticas públicas para a agricultura familiar no estado de São Paulo, Brasil. Boletim Alfenense de Geografia. Alfenas. v.1, n.2, p. 42-62, 2021. ISSN: 2764-1422. DOI: https://doi.org/10.29327/243949.1.2-5 
Fonte: Elaborado pelo autor com base nos dados do Fundo Nacional de Desenvolvimento da Educação (FNDE)

Por possuir mais tempo de existência e se tratar de um programa com maior experiência institucional de execução, e diversidade de modalidades, o PRONAF se constitui como o programa de maior porte dentre os analisados; tanto em termos de aporte de recursos, como de cobertura de municípios - sendo presente em 599 municípios do estado (93\%).

O valor médio dos contratos do PRONAF durante os anos analisados fica em torno de R \$ 25.100,oo com pouca oscilação do valor, independente da RA. Contudo, o gráfico 5 permite visualizar uma consolidada relação entre o número de contratos e o número estabelecimentos da agricultura familiar a partir das RAs demonstrando que o Programa é bem-sucedido em atender agricultores familiares de distintas realidades sociais e de variada retenção de capacidade técnica.

Gráfico 5 - Relação do PRONAF com Estabelecimentos da Agricultura Familiar (2011-2016)

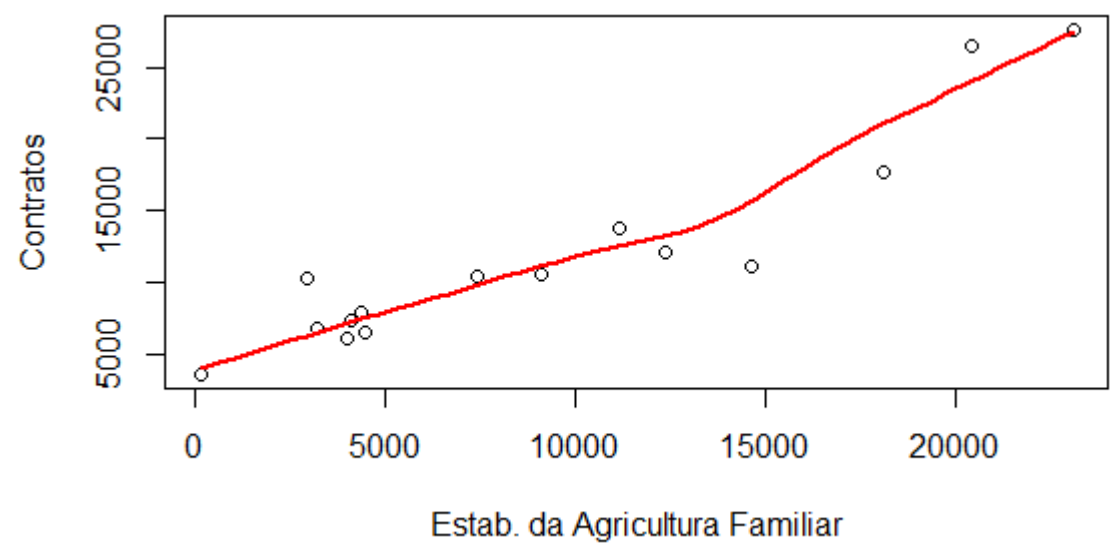

Fonte: Elaborado pelo autor com base nos dados sobre crédito rural do Banco Central do Brasil (2011-2016)

As análises das políticas públicas selecionadas demonstram o esforço do Estado brasileiro em promover o desenvolvimento humano a partir da garantia da SAN, utilizando-se da articulação de distintas intervenções.

\section{Considerações Finais}

O estudo demonstra que a intervenção do Estado na economia pode se dar de diversas maneiras. Destacam-se dois momentos distintos da ação pública, com o intuito a de modular a dinâmica do desenvolvimento rural no Brasil. A primeira, denominada modernização conservadora pela adoção massiva de tecnologias orientou a produção agrícola aos mercados externos, contudo, conduziu a um processo de formação de verdadeiras indústrias agrícolas concentrando o capital em um número restrito de latifundiários, que, por sua vez, levou à perda de autonomia dos agricultores familiares e ao aumento dos níveis de pobreza no meio rural de maneira generalizada. 
A orientação para um segundo modelo inicia-se a partir da década de 1990 e conduz a agricultura familiar a uma crescente importância no cenário rural brasileiro e à criação de instrumentos de promoção deste segmento, como o PRONAF em 1996. Com a chegada do Partido dos Trabalhadores ao poder em 2003, este modelo passa a contar com uma articulação mais intensa com políticas sociais e de transferência de renda, assumindo o protagonismo na elaboração da estratégia de desenvolvimento nacional apoiada na garantia da SAN, que viria a pautar a ação pública nos anos seguintes.

Observou-se que as políticas voltadas à agricultura familiar analisadas apresentam comportamentos variados em relação às RAs do estado de São Paulo, diferenciando-se a partir de suas delimitações e propósitos. O PAA demonstra atuar como importante instrumento para a redução de pobreza ao focalizar os produtores familiares nas RAs mais socialmente vulneráveis, ao mesmo tempo que contribui para a formação de mercados institucionais e à construção de sistema públicos de soberania alimentar descentralizados. Conjugando-se a outros programas, o PAA tem o escopo de suas ações ampliados o PRONAF atua de maneira a contribuir para o incremento na produtividade deste segmento e o PNAE apresenta mais uma alternativa de venda dos produtos estimulando a aquisição de seus produtos em redes públicas de ensino.

No caso analisado, a ação do Estado, orientada por forte participação social, demonstrou-se eficaz no sentido de mobilizar distintas fontes de recursos públicos e articulá-las, criando mecanismos eficazes de combate à pobreza e garantindo níveis satisfatórios de SAN e-condições favoráveis ao desenvolvimento humano.

O Brasil foi bem-sucedido ao lograr a saída do mapa da fome em 2014, contudo, os avanços alcançados encontram obstáculos decorrentes de uma descontinuidade que comprometem a sinergia construída entre as políticas públicas. Após o golpe de 2016, altera-se profundamente o programa de governo democraticamente eleito em 2014, conduzindo uma série de medidas antissociais e de austeridade, entre elas, a extinção do Ministério de Desenvolvimento Social e Combate à Fome (MDS), a principal fonte de recursos do PAA. Tais medidas impactam substancialmente a realidade do Brasil e indicam um aumento da pobreza entre 2016 e 2017 passando de $25,7 \%$ para $26,5 \%$ e da extrema pobreza de $6,6 \%$ para $7,4 \%$, acarretando um aumento da insegurança alimentar e um possível retorno do Brasil ao mapa da fome (IBGE).

A situação se agrava a partir de 2019, com a eleição de um governo ultraconservador descomprometido com as causas sociais e aliado à elite rural detentora dos latifúndios de monocultura exportadora. Além de aprovações recordes de agrotóxicos pela Agência Nacional de Vigilância Sanitária (ANVISA), o CONSEA, ferramenta essencial no combate à fome, é temporariamente fechado pela Medida Provisória que reorganiza os órgãos da Presidência da República e seus ministérios. Contudo, por meio de articulação de comissão mista no Congresso Federal, o processo é revertido e o CONSEA recriado.

Portanto é razoável levantar que, o novo governo, comprometido com o desmonte das conquistas sociais do governo anterior nas mais diversas áreas, lança sombras de dúvida sobre as políticas para a agricultura familiar, gerando profundas incertezas sobre a continuidade desse modelo de desenvolvimento agrário no Brasil. 


\section{Referências}

BACCARIN, J. G. (2011) Sistema de produção agropecuário brasileiro: características e evolução recente. São Paulo: Cultura Acadêmica, Universidade Estadual Paulista, Pró Reitoria de Graduação, 2a. Edição.

Brasil, Presidência da República (1965) Lei no 4.829, de 5 de novembro de 1965. Institucionaliza o crédito rural. Diário Oficial da União, Brasília, 1965. Disponível em:< http://www.planalto.gov.br/ccivil_03/leis/L4829.htm> Acesso em maio de 2019.

Brasil, Presidência da República (1996) Decreto $\mathrm{N}^{0}$ 1.946, de 28 de junho de 1996. Cria o Programa Nacional de Fortalecimento da Agricultura Familiar - PRONAF, e dá outras providências. Brasília-DF.

Brasil. Presidência da República (2006) Lei no 11.346, 15 de setembro de 2006. Cria o Sistema Nacional de Segurança Alimentar e Nutricional - Sisan - com vistas em assegurar o direito humano à alimentação adequada e dá outras providências. Diário Oficial da União, Brasília. Disponível em:<www.planalto.gov.br,ccivil_03/_ato2004-2006/2006/lei/l11346.htm> Acesso em: maio de 2019.

Brasil. Presidência da República (2009) Lei $\mathrm{n}^{0}$ 11.947, 16 de junho de 2009. Dispõe sobre o atendimento da alimentação escolar e do Programa Dinheiro Direto na Escola aos alunos da educação básica; altera as Leis nos 10.880, de 9 de junho de 2004, 11.273, de 6 de fevereiro de 2006, 11.507, de 20 de julho de 2007; revoga dispositivos da Medida Provisória no 2.178-36, de 24 de agosto de 2001, e a Lei no 8.913, de 12 de julho de 1994; e dá outras providências. Diário Oficial da União, Brasília. Disponível em:< http://www.planalto.gov.br/ccivil_03/_Ato2007-2010/2009/Lei/L11947.htm> Acesso em setembro de 2019.

BUAINAIN, A. M. (2012) A nova cara da pobreza rural: desafios para as políticas públicas. IICA, Brasília-DF.

CASTRO, J. (2005) Geografia da Fome. O dilema brasileiro: pão ou aço. Rio de Janeiro: O Cruzeiro.

DAVID, C. de.; CORRÊA, W. K. (2002) A política agrária e as transformações na agricultura brasileira: de 1960 aos dias atuais. Geosul, Florianópolis, v. 17, n. 33, p.23-43, jun.

DEL GROSSI, M.; GRAZIANO DA SILVA, J.; TAKAGI, M. (2001) Evolução da pobreza no Brasil - 1995/99. Campinas: Instituto de Economia, nov. (Texto para discussão, n. 104).

DELGADO et al. (2010) Brasil Rural em Debate. MDA, CONDRAF. Brasília - DF.

DELGADO, N. G. (2009) O papel e lugar do rural no desenvolvimento nacional. Brasília, DF: CONDRAF. (Texto para Discussão).

DRÈZE, J., \& SEN, A. K. (1992). Hunger and public action. Oxford, England, Clarendon Press.

EECKE W. (1999) Public goods: An ideal concept. Journal of Socio-Economics; 28:139-156. 
FAO (1996) Declaração de Roma Sobre a Segurança Alimentar Mundial e Plano de Acção da Cimeira Mundial da Alimentação. Roma, Itália.

FAO (2014a) O estado da segurança alimentar e nutricional no Brasil: Um Retrato

FAO (2018) The State of Food Insecurity and Nutrition in the World

FAO, IFAD, UNICEF, WFP and WHO (2018) The State of Food Security and Nutrition in the World 2018. Building climate resilience for food security and nutrition. Rome, FAO.

FAO/INCRA (1994) Diretrizes de política agrária e desenvolvimento sustentável.

FIAN International (2014). G8 New Alliance for Food security and Nutrition in Africa: a critical analysis form a human rights perspective. Heidelberg: FIAN International.

GOODMANM, D. E., SORJ B., WILKINSON, K. (1985) Agroindústria, políticas públicas e estruturas sociais rurais: análise recentes sobre a agricultura brasileira. Revista de Economia Política. São Paulo, v. 5, n. 4, outubro/dezembro.

GRAZIANO DA SILVA, J.; GÓMEZ, S. E.; CASTAÑEDA, R. S. (Ed.) (2009) Boom agrícola y persistencia de la pobreza rural en América Latina. Santiago, Chile: Escritório Regional da FAO para América Latina.

Grupo Gestor do PAA (2011) Balanço de Avaliação da Execução do Programa de Aquisição de Alimentos - PAA 2003 a 201O. MDS, Brasília-DF.

IBGE (2010). Avaliação Nutricional da Disponibilidade Domiciliar de Alimentos no Brasil. Disponível em: <https://www.ibge.gov.br/>. Acesso em junho de 2019.

KAGEYAMA, A. A. et al. (1990) O novo padrão agrícola brasileiro: do complexo rural aos complexos agroindustriais. In: DELGADO, G. C. et al. (Orgs.). Agricultura e políticas públicas. IPEA, Brasília-DF, pp. 113-224.

Langley, P \& Mellor, M. (2002). 'Economy', sustainability nad sites of transformative space. News Political Economy, 7(1):49-65.

MALUF, R.S., 2000. O novo contexto internacional da segurança alimentar. In: BÉLIK, W. \& MALUF, R.S. (Orgs.) Abastecimento e Segurança alimentar: os limites da liberalização. Campinas:Unicamp/Redcapa.

MALUF, R.S., 2007, Segurança Alimentar e Nutricional: conceitos fundamentais. Petrópolis, Vozes.

MALUF, R.S., DOS REIS, M.C., 2013. Conceitos e Princípios de Segurança Alimentar e Nutricional. In: Rocha, C., Burlandy, L., Magalhães, R., (Orgs.) Segurança Alimentar e Nutricional: perspectivas, aprendizados e desafios para as políticas públicas. Rio de Janeiro: Editora Fiocruz.

MATTEI, L. (2007) Políticas de Apoio ao Desenvolvimento da Agricultura Familiar no Brasil: O Caso Recente do Pronaf. Revista Econômica do Nordeste, Fortaleza, v. 38, n. 1, p. 143-158, jan-mar.

MATTEI, L. (2017) Crise Econômica e a Visão das Políticas de Desenvolvimento Rural nos Anos 1990. O Legado das Políticas Públicas de Desenvolvimento Rural para a Inclusão Socioprodutiva no Brasil, Vol. 24, IICA. 
MAZOYER, M., ROUDART, L. (2002). Histoire des agricultures du monde: Du néolithique à la crise contemporaine.

Ministério do Desenvolvimento Social e Combate à Fome (2010). Bolsa família. Disponível em: <http://www. mds.gov.br>. Acesso em setembro de 2019.

OLIVEIRA, J.A., (2015) Políticas Públicas para Agricultura Familiar: o Caso do Programa de Aquisição de Alimentos (PAA) no Estado de São Paulo, Brasil. Dissertação de Mestrado: Instituto de Geociências e Ciências Exatas do Campus de Rio Claro, da Universidade Estadual Paulista "Júlio de Mesquita Filho".

ONU (1966) Pacto Internacional sobre os Direitos Econômicos, Sociais e Culturais. Assembléia Geral das Nações Unidas, de 16 de Dezembro de 1966, Nova York.

PEREIRA, P.A. (1999). A metamorfose da questão social e reestruturação das políticas sociais. Capacitação em serviço social e política social, módulo 1: Política Social. Brasília: CFESS/ABEPSS/CEA/NED-UNB.

PEREIRA, R. L.; OLIVEIRA, J. O.; DENISE, B. P. da. (2014) Evolução dos recursos e distribuição geográfica do Programa Nacional de Fortalecimento da Agricultura Familiar no Brasil entre 1999 e 2012. In: Encontro Nacional de Geografia Agrária (ENGA), XXII., 2014, Natal. Anais. Natal: ENGA, 2014. P. 342351.

PICOLOTTO, Everton Lazzaretti. (2014) Os Atores da Construção da Categoria Agricultura Familiar no Brasil. Revista de Economia e Sociologia Rural, 52(Suppl. 1), 63-84.

POLANYI, K. (1944) The Great Transformation, Boston: Beacon Press.

ROCHA, C. (2007) Food Insecurity as Market Failure: A Contribution from Economics, Journal of Hunger \& Environmental Nutrition, 1:4, 5-22.

SEN, Amartya (2001) Development as freedom. Oxford: Oxford University Press.

SILVA, J. G. (2009) Zero Hunger and Territories of Citizenship: promoting food security in Brazil's Rural. In: Von Braun, J.; Vargas, R.; Pandya-Corch, R. The poorest and hungry: assessments, analyses, and actions: an IFPRI 2020 book.

United Nations (1995) Report of the World Summit for Social Development.

VALENTE, F.L.S., D.Córdova Montes. (2016) The human right to adequate food and nutrition within a framework of food sovereignty: towards social inclusion and the reduction of inequalities. In Policy in Focus 12: 7-11. IPC-IG, Brasília.

WEIMER, D.L.; VINING, A.R. (1999) Policy Analysis-Concepts and Practice. Upper Saddle River: Prentice Hall. 